\title{
EXPERT PANEL OVERSIGHT COMMITTEE ASSESSMENT OF FISCAL YEAR 2008 CORROSION AND STRESS CORROSION CRACKING SIMULANT TESTING PROGRAM
}

\author{
KD Boomer \\ WRPS \\ Richland, WA 99352 \\ U.S. Department of Energy Contract DE-AC27-08RV14800

$\begin{array}{lll}\text { EDT/ECN: } & \text { DRF } & \text { UC: NA } \\ \text { Cost Center: } & \text { NA } & \text { Charge Code: NA } \\ \text { B\&R Code: } & \text { NA } & \text { Total Pages: } 9\end{array}$

Key Words: EPOC, RPP-RPT-22126, DST, SCC, Workshop for Hanford Site Double-Shell Tank Waste Chemistry Organization, Corrosion Cracking Simulant Testing Program

Abstract: The Expert Panel Oversight Committee (EPOC) has been overseeing the implementation of selected parts of Recommendation III of the final report, Expert Panel Workshop for Hanford Site DoubleShell Tank Waste Chemistry Optimization, RPP-RPT-22126. Recommendation III provided four specific requirements necessary for Panel approval of a proposal to revise the chemistry control limits for the Double-Shell Tanks (DSTs). One of the more significant requirements was successful performance of an accelerated stress corrosion cracking (SCC) expiermental program. This testing program has evaluated the optimization of the chemistry controls to prevent corrosion in the interstitial liquid and superatant regions of the DSTs.

TRADEMARK DISCLAIMER. Reference herein to any specific commercial product, process, or service by trade name, trademark, manufacturer, or otherwise, does not necessarily constitute or imply its endorsement, recommendation, or favoring by the United States Government or any agency thereof or its contractors or subcontractors.
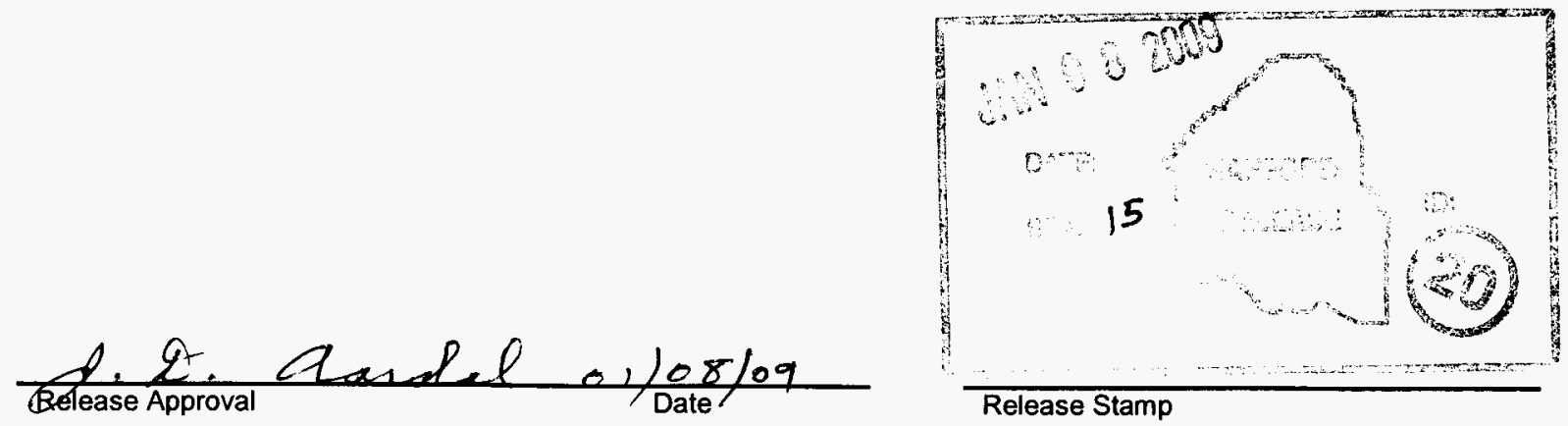

Approved For Public Release 
MICHAEL T. TERRY, P.E.

323 Skagit St.

Richland, Washington 99354

(509) 531-0920

November 7, 2008

Mr. Herbert S. Berman

Washington River Protection Solutions

P.O. Box 1500, MSIN R2-58

Richland, Washington 99352

\section{SUBJECT: EXPERT PANEL OVERSIGHT COMMITTEE ASSESSMENT OF FISCAL YEAR 2008 CORROSION AND STRESS CORROSION CRACKING SIMULANT TESTING PROGRAM}

Dear Mr. Berman,

The Expert Panel Oversight Committee (EPOC) has been overseeing the implementation of selected parts of Recommendation III of the final report, Expert Panel Workshop for Hanford Site Double-Shell Tank Waste Chemistry Optimization, RPP- RPT-22126. Recommendation III provided four specific requirements necessary for Panel approval of a proposal to revise the chemistry control limits for the Double-Shell Tanks (DSTs). One of the more significant requirements was successful performance of an accelerated stress corrosion cracking (SCC) experimental program. This testing program has evaluated the optimization of the chemistry controls to prevent corrosion in the interstitial liquid and supernatant regions of the DSTs.

During August of this year, the EPOC gathered at Hanford to discuss the results of the testing to date. Results of those deliberations were reported in a letter from the EPOC. ${ }^{1}$ We concluded at that time that the testing program for the interstitial liquids in the solid layers was complete with respect to minimum hydroxide ion concentration and the ratio of nitrite ion to nitrate ion.

However, subsequent study indicates hydroxide-ion-promoted SCC (as distinguished from nitrate SCC) cannot yet be completely eliminated from consideration for several DST waste layers that have high hydroxide ion concentrations (i.e., greater than two molar hydroxide). The relatively low temperature of these DSTs and their stress-relieved construction presumably mitigate any

${ }^{1}$ RPP-ASMT-39069, Rev. 0, Summary and Recommendations of the Expert Panel Oversight Committee Meeting on Double-Shell Tank Corrosion Monitoring and Testing Held August 4 and 5, 2008, Richland, Washington, 2008.

Double-Shell Tank Corrosion Monitoring and Testing Expert Panel Oversight Committee Members

- John Beavers Gerald Frankel 
SCC threat. However, SSR tests with simulants of these hydroxide-ion rich wastes will need to be completed before the results of this program can be used to deem all interstitial liquids and supernatant layers of the DST benign with respect to SCC and to provide a technical basis for recommendations regarding the upper hydroxide ion chemistry limits in the DST wastes.

We further concluded that the testing program for pitting corrosion and SCC of the present supernatant layers of the DSTs could be completed by carrying out a short test program. Finally, we noted that additional pitting corrosion and SCC testing is required in order to establish the chemistry limits for tanks that will be used to receive waste retrieved from the Single-Shell Tanks.

The final report of findings from the FY2008 corrosion testing program, released in late September by ARES Corporation and CC Technologies, Inc. (CCT), captured the results of the testing performed to develop a comprehensive understanding of the corrosivity of the tank wastes stored in DSTs by using bounding waste simulants. The simulants used were primarily from Tanks 241-AP-105, 241-SY-103 and 241-AW-105. ${ }^{2}$ These tanks were selected following a critical review of wastes chemistries by the EPOC. Additional tests were conducted using simulants of the wastes stored in Tanks 241-AZ-102, 241-SY-101, and 241-AY-101. The test program placed particular emphasis on defining the range of tank waste chemistries that do not induce the onset of localized forms of corrosion, particularly pitting and SCC. Based on the information in the section on Tank Waste Chemistry below, we must refine the conclusions and recommendations stated in Reference 1 only for those DSTs with high hydroxide concentrations (i.e., $>2 \mathrm{M}$ ), but we fully support changes to the chemistry control limits for the majority of DSTs at lower hydroxide ion concentrations. We also offer the following additional observations and recommendations.

The EPOC sees no need for core sampling of DSTs to determine the corrosion chemistry of the interstitial liquids in Tanks AN-103 and AN-104. The recent work has demonstrated that the anticipated chemistry changes in these tanks will not adversely influence their integrity because the ongoing conversion of nitrate ion to nitrite ion offers protection against corrosion and the wastes have more than sufficient hydroxide ion to alleviate concerns about reaching the bounding lower $\mathrm{pH}$ limit near $\mathrm{pH} 10$.

\section{$\underline{\text { Tank Waste Chemistry }}$}

Simulants from the six principal waste types in the DSTs (Complexed Concentrate, Double Shell Slurry and Double Shell Slurry Feed, Dilute Double Shell Slurry Feed, Dilute Non-Complexed Waste, PUREX Decladding Waste, and PUREX Aging Waste) have been examined in the course of the study. From these waste types, simulants of the wastes with the highest known concentrations of sulfate ion, carbonate ion, chloride ion, and fluoride ion in the DSTs have been investigated for their propensity to cause pitting or SCC. Simulants with the bounding low concentrations of nitrite ion, the bounding high concentration of nitrate ion and the bounding lowest value of the nitrite ion/nitrate ion concentration ratio have been studied. Artificial mixtures with large variations in the absolute concentrations of nitrite ion (from 0 to $7 \mathrm{M}$ ) and nitrate ion (from 0 to $5 \mathrm{M}$ ) and the nitrite ion/nitrate ion ratio have been tested.

\footnotetext{
${ }^{2}$ RPP-RPT-37505, Rev. 0, Effects of Chemistry and Other Variables on Corrosion and Stress Corrosion Cracking in Hanford Double-Shell Tanks, Richland, Washington, 2008.
} 
The work that had been accomplished with simulants of the present day interstitial liquids was reviewed at the April EPOC meeting held at CC Technologies. Prior study of simulants of the liquids from Tanks 241-AY-101 and 241-AY-102 and the present and future interstitial liquids in the solid layers of Tanks 241-AN-102 and 241-AN-107 were considered in our earlier letters, where it was concluded that they were benign with respect to SCC. A survey of the compositions of the liquids in the solid layers of the other DSTs indicated the interstitial liquids were generally less prone to SCC than these wastes. However, the Committee recommended that the interstitial liquid from the solid layer in Tank 241-AZ-102 be investigated because the tank temperature is much higher, $77^{\circ} \mathrm{C}$, than the other tanks. Accordingly, a simulant of this waste was investigated at $77^{\circ} \mathrm{C}$ during the $\mathrm{FY} 2008$ program. It was found to be benign.

Additional work was carried out during the year with simulants that had low nitrite ion to nitrate ion ratios at potentials intermediate between the open circuit potential (OCP) and $0 \mathrm{mV}$ (SCE). SCC did not occur with these simulants at $-100 \mathrm{mV}$ (SCE), but SCC was observed with one simulant at $-50 \mathrm{mV}$ (SCE). The results of these tests are compatible with previous findings that also showed SCC did not occur at $-100 \mathrm{mV}$ (SCE), but did sometimes occur at $-50 \mathrm{mV}$ (SCE). The upper SCC potential boundary for these nitrate ion rich wastes appears to be between -100 and $0 \mathrm{mV}$ (SCE).

The influence of $\mathrm{pH}$ has also been explored. Our conclusions about the propensity for pitting and $\mathrm{SCC}$ corrosion in wastes at the lower bounding $\mathrm{pH}$ limit have been presented in earlier letters. One unresolved issue that has recently surfaced is the potential for caustic cracking in the supernatant and solid layers of the DSTs with high concentrations of hydroxide ion. These tanks contain double shell slurry and double shell slurry feed; an example is Tank 241-AW-101, which has a concentration of about $5.8 \mathrm{M}$ hydroxide ion. This issue should be addressed in the FY 2009 testing program.

\section{Stress Corrosion Cracking - Slow Strain Rate Tests}

The EPOC selected waste compositions for Tanks 241-SY-103, 241-AW-105, 241-AZ-102, and 241-AP-105 as bounding limits for corrosive ionic species or operating temperature in the DST system. The chemical composition data for the DST tank wastes were obtained from several technical reports including RPP-13639 and the TWINS database. ${ }^{3}$

The Tank 241-SY-103 present interstitial liquid (SY103-PIL) simulant was tested because of its high chloride concentration. This simulant was deemed to be benign with respect to SCC. This low propensity for SCC was probably the result of the high nitrite to nitrate ratio (1.48), the high absolute nitrite concentration $(2.91 \mathrm{M})$, and the high $\mathrm{pH}(14)$.

The Tank 241-AW-105 simulants (AW105-PIL and AW105 present supernate composition (AW105-PSC)) were tested because of their high fluoride concentrations and low nitrite to nitrate ratios. These simulants were deemed to be benign with respect to SCC. This low propensity for SCC was probably the result of the low nitrate concentration $(0.41$ to $0.44 \mathrm{M})$, the presence of other inhibitors in the simulant, and the high $\mathrm{pH}(>13)$.

The Tank 241-AZ-102 PIL (AZ102-PIL) simulant was tested because of the high operating temperature $\left(77^{\circ} \mathrm{C}\right)$ of the tank. This simulant was deemed to be benign with respect to SCC.

${ }^{3}$ RPP-13639, Rev. 4, Caustic Limits Report-May 31, 2007, Richland, Washington, 2007. 
This low propensity for SCC was probably due to the high nitrite/nitrate ratio of the simulant (8.4). This result again confirms the inhibitory nature of nitrite.

The Tank 241-AP-105-PSC (AP105-PSC) simulant was tested because of its low nitrite to nitrate ratio. This simulant promoted $\mathrm{SCC}$, even at the free corrosion potential. This behavior was attributed to the high nitrate concentration $(3.58 \mathrm{M})$, low nitrite to nitrate ratio, and relatively noble free corrosion potential. Based on all of the testing performed to date, this observation is not altogether surprising. SCC was observed at the free corrosion potential in $5 \mathrm{M}$ nitrate and in one other waste simulant in which the nitrite was removed (Tank 241-AN-107). The observation of SCC in these simulants containing low nitrite concentrations suggests that there is some minimum nitrite concentration or nitrite to nitrate ratio below which SCC is likely to affect tank integrity. It should be pointed out that the supernatant composition in Tank 241-AP-105 has been adjusted, producing a mixed simulant with a higher nitrite concentration and nitrite to nitrate ratio than the AP105-PSC simulant.

\section{Pitting Corrosion}

Cyclic polarization experiments were performed during the past year on fully immersed tank samples in simulants of Tanks 241-AP-105, 241-SY-103 present interstitial liquid (PIL), 241AW-105, 241-AZ-102, 241-SY-101, and 241-AY-101 condensate surface layer (CSL). For each chemistry composition studied, except for a low pH simulant AY101-CSL, as discussed below, no evidence of pitting corrosion was found. It should be emphasized that the experiments involved polarizing to very high potentials, so they were extremely aggressive from the perspective of potential. The lack of pitting corrosion after these cyclic polarization tests indicates that there is a very low likelihood of pitting corrosion at regions away from the liquid/air interface (LAI).

The AY101-CSL chemistry was a simulant of a dilute layer formed as the result of condensate return to Tank 241-AY-101 from the 241-AZ-301 catch tank. Pitting corrosion was observed for a simulant of Tank 241-AY-101 CSL at $\mathrm{pH}$ values of 11.8 and 12.3 at $50^{\circ} \mathrm{C}$, but not at $\mathrm{pH} 12.8$ at that temperature, and not at $\mathrm{pH} 11.8$ at room temperature. The results indicate that even this condensate surface layer is benign at room temperature and at slightly elevated temperatures if the $\mathrm{pH}$ is raised slightly. The $\mathrm{pH}$ of the surface layer has been adjusted to 12.8 and the tank temperature is considerably less than $50^{\circ} \mathrm{C}$, so there is presently no cause for concern. In summary, the pitting susceptibility of the simulants studied this year is very low.

\section{Liquid-Air Interface Corrosion}

LAI corrosion was identified as a significant concern in Tank 241-AW-105 and Tank 241-AP-105 simulants. While there is not a complete understanding of the mechanism of the attack, important factors that appear to promote the attack include low nitrite to nitrate ratio, noble polarized potentials, elevated temperature, $\mathrm{CO}_{2}$ in the vapor space above the liquid, and stagnant interface conditions. LAI corrosion is a potential leak integrity threat to these and other tanks with similar low nitrite to nitrate ratios and tanks used for retrieval operations. It is interesting that this LAI corrosion occurred despite the fact that the bulk pHs were high $(>13)$.

As discussed more completely in a previous transmission (Reference 1), the CCT observation that failure occurred at "high $\mathrm{pH}$ " is rationally related to the localized nature of the LAI corrosion process in which the introduction of carbon dioxide from the atmosphere changes the local $\mathrm{pH}$ and in which the rate of transport of hydroxide ion from the bulk solution to the corrosion site is too small to prevent the development of the more acidic environment at the LAI. Hydroxide ion might be just as effective as nitrite ion at preventing LAI corrosion, but unfortunately, it might 
not available at the necessary LAI location. This new understanding can lead to a major improvement in the prevention of LAI corrosion by chemistry control (i.e., nitrite limits as opposed to hydroxide limits).

\section{Stress Corrosion Cracking - Fracture Mechanics Tests}

A relatively small number of crack growth tests were performed in FY 2008 and these tests were performed using a relatively new technique, referred to as a dynamic $\mathrm{K}$ test. With this technique, a pre-cracked compact type specimen is exposed to constant displacement rate loading, which is similar to the loading used in a slow strain rate test, followed by constant displacement. The idea is to initiate SCC in the constant displacement rate step. In the constant displacement step, the crack is allowed to extend, resulting in a decrease in the load, and the crack finally arrests at the threshold stress intensity factor for SCC $\left(\mathrm{K}_{\mathrm{thSCC}}\right)$. The results of the FY 2008 testing are promising but, in the few cases where comparisons with previous research were possible, the dynamic $\mathrm{K}$ test technique appears to be giving higher threshold values than the constant load technique previously used. For example, in Test CT-13, the $\mathrm{K}_{\text {thSCC }}$ was estimated to be around 35 ksi $\sqrt{ }$ in the $\mathrm{AN}-107$ chemistry at $0 \mathrm{mV}$ polarized potential and $50^{\circ} \mathrm{C}$; whereas intergranular crack growth was reported in one constant load test at a much lower applied $\mathrm{K}(10 \mathrm{ksi}$ in $)$ but otherwise under the same test conditions. This observation is surprising in that the dynamic $\mathrm{K}$ test was selected to provide a more conservative estimate of $\mathrm{K}_{\mathrm{thSCC}}$. It should be pointed out that, in the constant load tests, the presence of intergranular SCC was established based on metallography and was not confirmed by means of a scanning electron microscope examination; the analysis might have been in error. Further analysis and additional testing will be necessary to resolve this issue.

\section{Conclusions}

The 2008 research results are consistent with previous research results in that nitrite ion is a strong inhibitor for pitting corrosion, SCC, and LAI.

The cyclic polarization experiments performed during the past year indicate that there is a very low likelihood of pitting corrosion at regions away from the LAI for all of the simulants studied.

The SSR tests indicate that there is a very low likelihood of SCC for all of the simulants studied in the 2008 research, with the exception of the AP-105-PSC simulant.

The AP-105-PSC simulant promoted SCC, even at the free corrosion potential. This behavior was attributed to the high nitrate concentration $(3.58 \mathrm{M})$, low nitrite to nitrate ratio, and relatively noble free corrosion potential.

LAI corrosion was identified as a significant concern in Tank 241-AW-105 and 241-AP-105 simulants. Factors that appear to promote the attack include low nitrite to nitrate ratio, noble polarized potentials, elevated temperature, $\mathrm{CO}_{2}$ in the vapor space above the liquid and stagnant interface conditions.

Any supernatant chemistry specification change will need to wait on the results of the vapor space corrosion (VSC) testing, to ensure that VSC will not be adversely affected by the expected changes in supernatant chemistry.

The EPOC reaffirms the conclusions form the August EPOC meeting report (Reference 1), with the exception that the potential issue of caustic cracking in a few high hydroxide wastes must be 
addressed before the testing program for the interstitial liquids in the solid layers is considered complete.

Finally, the EPOC still endorses the installation and use of an in-tank corrosion monitoring systems. Corrosion monitoring systems should facilitate corrosion rate monitoring (via the Electrical Resistance technique) and measurement of tank corrosion potential using either primary and/or secondary reference electrodes. The corrosion monitoring system should also contain passive coupons that can be periodically removed and examined to verify the expected low levels of waste corrosivity. The EPOC notes that, if the installed corrosion probe exhibits increased corrosion activity or drifting of the OCP towards the sensitivity regions, Washington River Protection Solutions should consider increasing the frequency of ultrasonic testing examinations, and/or perform additional waste sampling to verify chemistry conditions.

\section{Recommendations}

The potential issue of caustic cracking in a few of the wastes as a result of the high hydroxide concentration remains unresolved, and should be investigated as part of the FY 2009 testing program. This activity will complete the testing program for the interstitial liquids in the present and future solid layers of the DSTs. The results of this test program can then be used to modify the chemistry limits for the interstitial liquids.

The EPOC sees no need for core sampling of Tanks 241-AN-103 and 241-AN-104 to determine the corrosion chemistry of the interstitial liquids.

Additionally, the EPOC reaffirms the recommendations shown in Attachment 1 of the EPOC meeting report (Reference 1) and the rationale behind each of them. In summary, these recommendations included the following items.

- Investigate the effects of elevated temperature, ammonia concentration, and pertechnetates on SCC.

- Determine the critical potentials and concentrations associated with SCC using a statistical experimental design approach.

- Study LAI corrosion using a phased approach by initially focusing on the effects of temperature, steel microstructure, surface condition, and ammonia to determine if any of these are strongly mitigating factors.

- Verify experimentally the thermodynamic findings that have already been obtained related to the consequences of drying condensates on vapor space corrosion, and perform any necessary additional modeling work.

- Carry out additional thermodynamic modeling of the drying of supernatant and verify experimentally the thermodynamic predictions that have already been reported.

- Implement a multi-phase stress intensity factor and crack growth rate testing activity to close out this work.

- Collect more data from the $241-\mathrm{AN}-102$ corrosion probe to establish data quality objectives because there is insufficient data at the present time. 
In closing the EPOC is pleased with the positiwe response giwen to past recommendations and appreciates the opportunity to continue supporting this important work. The continuation of the studi es recommetided in this letter and referenced documents will permt the characterization of the corrosivity of all Hanfort DST wastes, prowide a defensible technical basis for assessing is and for optimizing waste chemistry, and help to ensure DSTs integrity for the life of the currently plantred mission.

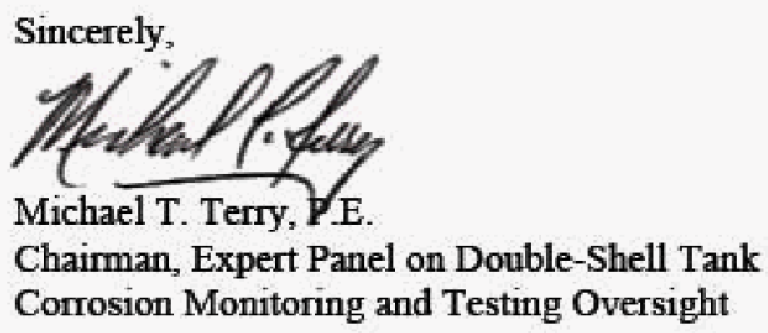

